\section{Venus' light crust hinders its planetary-scale subduction}

\author{
JUNXING CHEN ${ }^{1}, \mathrm{XU} \mathrm{CHU}^{1}$, MING TANG ${ }^{2}$ AND JIHUA \\ $\mathrm{HAO}^{3}$ \\ ${ }^{1}$ University of Toronto \\ ${ }^{2}$ Peking University \\ ${ }^{3}$ University of Science and Technology of China \\ Presenting Author: junxing.chen@mail.utoronto.ca
}

Terrestrial planets Venus and Earth have similar sizes, masses, and compositions. Global-scale subduction is unique on Earth, acting as a major carbon sink that transfers carbon from the surface to the interior. Venus, by contrast, lacks such long-lived subduction and thus a long-term carbon sink, which contributes to the thick green-house atmosphere. The high surface temperature prevents plate tectonics on modern Venus. Had Venus been a cool planet with a liquid ocean, would it develop global-scale plate tectonics as Earth did? To answer the question from a petrologist's perspective, we examined Venus's slab densities at hypothesized subduction-zone conditions. In our phase equilibria modeling, we used the bulk compositions of Venusian crust measured by the onboard XRF instruments of USSR spacecrafts Venera 13, Venera 14, and Vega 2. Our simulations show that eclogite facies is reached at a greater depth on Venus than on Earth, and Venus's slab densities are consistently lower than that of Earth's. For example, the average Venus's slab density may be lower than $3.2 \mathrm{~g} / \mathrm{cm}^{3}$ at $55 \mathrm{~km}$ along a warm geotherm $\left(11.3^{\circ} \mathrm{C} / \mathrm{km}\right)$, whereas that of the Proterozoic Earth's slab may have exceeded $3.3 \mathrm{~g} / \mathrm{cm}^{3}$ [1] and approached mantle density. Venus was resurfaced in the past hundreds of millions of years, so its surface rocks represent modern crust. In the early history of Venus, the melting of a hotter mantle would have produced crustal rocks of higher $\mathrm{Mg}$ concentrations. $\mathrm{Mg}$ rich bulk composition results in even lighter metamorphic rocks, especially along a warm geotherm. Although plume-induced downwelling likely exists on Venus, but unlike early Earth, the dipping of the Venusian crustal rocks to mantle depth may fail to develop into self-sustained subduction. In sum, we speculate that the lack of sufficient density contrast between the metamorphosed slab and mantle rocks, and the slightly smaller gravitational acceleration, may have impeded self-sustained subduction on a planetary scale on Venus and diverged the evolution of its surface environment from that of Earth.

[1] Emergence of blueschists on Earth linked to secular changes in oceanic crust composition, Palin, R. \& White R.(2016), Nature Geosci 9, 60-64
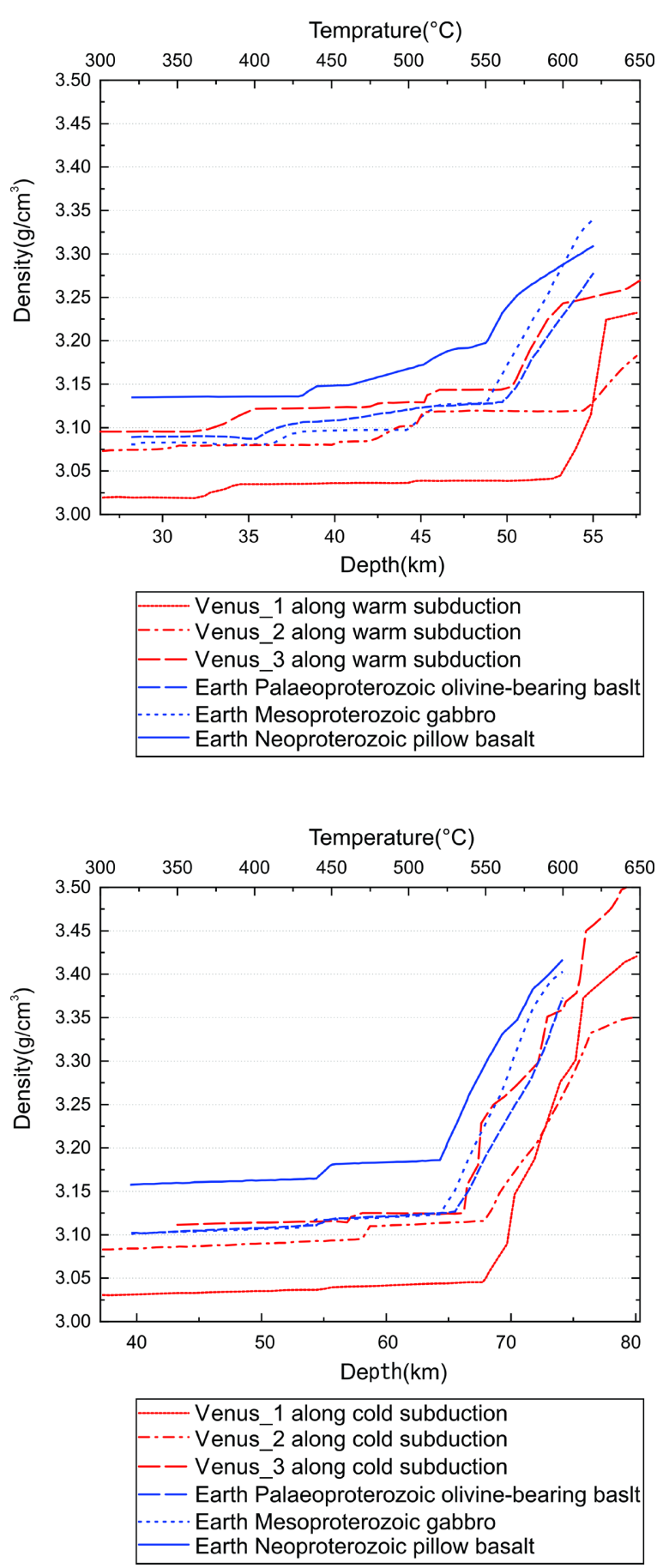